\title{
A Nomogram for Predicting Laparoscopic and Endoscopic Cooperative Surgery during the Endoscopic Resection of Subepithelial Tumors of the Upper Gastrointestinal Tract
}

\author{
Shun-Wen Hsiao ${ }^{1,2,+}$, Mei-Wen Chen ${ }^{3,4}$, Chia-Wei Yang ${ }^{1,+}$, Kuo-Hua Lin ${ }^{5}$, Yang-Yuan Chen ${ }^{1,2,6}$, \\ Chew-Teng Kor ${ }^{7,8}$, Siou-Ping Huang ${ }^{1}$ (D) and Hsu-Heng Yen ${ }^{1,9,10,11, *(D)}$ \\ 1 Division of Gastroenterology, Changhua Christian Hospital, Changhua 500, Taiwan; \\ 177099@cch.org.tw (S.-W.H.); $97601 @$ cch.org.tw (C.-W.Y.); 27716@cch.org.tw (Y.-Y.C.); \\ 182972@cch.org.tw (S.-P.H.) \\ 2 Division of Gastroenterology, Yuanlin Christian Hospital, Changhua 500, Taiwan \\ 3 Department of Information Management, Chien-Kuo Technology University, Chunghua 500, Taiwan; \\ 135442@cch.org.tw \\ 4 Department of Tumor Center, Changhua Christian Hospital, Changhua 500, Taiwan \\ 5 Department of General Surgery, Changhua Christian Hospital, Changhua 500, Taiwan; 120380@cch.org.tw \\ 6 Department of Hospitality Management, MingDao University, Changhua 500, Taiwan \\ 7 Big Data Center, Changhua Christian Hospital, Changhua 500, Taiwan; 179297@cch.org.tw \\ 8 Graduate Institute of Statistics and Information Science, National Changhua University of Education, \\ Changhua 500, Taiwan \\ check for \\ updates \\ Citation: Hsiao, S.-W.; Chen, M.-W.; \\ Yang, C.-W.; Lin, K.-H.; Chen, Y.-Y.; \\ Kor, C.-T.; Huang, S.-P.; Yen, H.-H. A \\ 9 General Education Center, Chienkuo Technology University, Changhua 500, Taiwan \\ 10 Department of Electrical Engineering, Chung Yuan Christian University, Taoyuan 320, Taiwan \\ 11 College of Medicine, National Chung Hsing University, Taichung 400, Taiwan \\ * Correspondence: 91646@cch.org.tw or blaneyen@gmail.com \\ + Hsiao Shun-Wen and Chia-Wei Yang contributed equally to this work.
} Nomogram for Predicting

Laparoscopic and Endoscopic Cooperative Surgery during the Endoscopic Resection of Subepithelial Tumors of the Upper Gastrointestinal Tract. Diagnostics 2021, 11, 2160. https://doi.org/10.3390/ diagnostics 11112160

Academic Editor: Keun Ho Ryu

Received: 14 October 2021

Accepted: 17 November 2021

Published: 22 November 2021

Publisher's Note: MDPI stays neutral with regard to jurisdictional claims in published maps and institutional affiliations.

Copyright: (c) 2021 by the authors. Licensee MDPI, Basel, Switzerland. This article is an open access article distributed under the terms and conditions of the Creative Commons Attribution (CC BY) license (https:// creativecommons.org/licenses/by/ $4.0 /)$.

\begin{abstract}
Background: Considering the widespread use of esophagogastroduodenoscopy, the prevalence of upper gastrointestinal (GI) subepithelial tumors (SET) increases. For relatively safer removal of upper GI SETs, endoscopic submucosal dissection (ESD) has been developed as an alternative to surgery. This study aimed to analyze the outcome of endoscopic resection for SETs and develop a prediction model for the need for laparoscopic and endoscopic cooperative surgery (LECS) during the procedure. Method: We retrospectively analyzed 123 patients who underwent endoscopic resection for upper GI SETs between January 2012 and December 2020 at our institution. Intraoperatively, they underwent ESD or submucosal tunneling endoscopic resection (STER). Results: ESD and STER were performed in 107 and 16 patients, respectively. The median age was 55 years, and the average tumor size was $1.5 \mathrm{~cm}$. En bloc resection was achieved in 114 patients (92.7\%). The median follow-up duration was 242 days without recurrence. Perforation occurred in 47 patients $(38.2 \%)$, and 30 patients $(24.4 \%)$ underwent LECS. Most perforations occurred in the fundus. Through multivariable analysis, we built a nomogram that can predict LECS requirement according to tumor location, size, patient age, and sex. The prediction model exhibited good discrimination ability, with an area under the curve (AUC) of 0.893. Conclusions: Endoscopic resection is a noninvasive procedure for small upper-GI SETs. Most perforations can be successfully managed endoscopically. The prediction model for LECS requirement is useful in treatment planning.
\end{abstract}

Keywords: subepithelial tumor; endoscopic resection; laparoscopy; GIST

\section{Introduction}

Subepithelial tumors (SETs) originate from muscularis mucosa, submucosa, or muscularis propria. In a Swedish population, the incidence of gastric SETs was reported to be $0.36 \%$ [1]. Considering the widespread use of esophagogastroduodenoscopy (EGD), the incidence increases. Recently in South Korea, the prevalence of gastric SETs was 1.7\%, 
and increased to $3.0 \%$ in patients in their 60s [2]. Endoscopic ultrasound (EUS) can reveal the layer of origin, tumor size, and internal echotexture. However, EUS alone has been less accurate in diagnosing hypoechoic lesions with three to four layers [3]. Hence, histopathological diagnosis remains the gold standard. Current guidelines recommend surgical resection for patients with symptoms, tumor size $>20 \mathrm{~mm}$, or high-risk features [4-6]. However, laparoscopic wedge resection may be difficult for tumors with a smaller size, protruding into the inner cavity of the stomach, or located in the lesser curvature or nearby esophagogastric junction [7]. Nevertheless, endoscopic submucosal dissection (ESD) has been considered as an effective and relatively safe method for removing superficial mucosal tumors, such as adenoma or early cancer, as well as SETs [8,9]. In this study, we aimed to retrospectively analyze the outcome of endoscopic resection for upper gastrointestinal (GI) SETs in our hospital, and develop a prediction model for the need of laparoscopic and endoscopic cooperative surgery (LECS) for the procedure.

\section{Materials \& Methods}

\subsection{Inclusion Criteria and Exclusion Criteria of the Study Population}

We retrospectively analyzed the medical records of patients who received endoscopic treatment with intent of laparoscopic and endoscopic cooperative surgery (LECS) during the procedure for upper GI SETs between January 2012 and December 2020 at our institution. All patients received EUS evaluation or abdominal computed tomography to identify the tumor size, invasive depth, and differential diagnosis before endoscopic resection. Endoscopic tumor resection was performed in those with highly suspected gastrointestinal stromal tumors (GISTs) on EUS, tumor size $>20 \mathrm{~mm}$, or patient request. During the resection, patients underwent either ESD or submucosal tunneling endoscopic resection (STER), depending on the discretion of the endoscopist on the basis of the EGD/EUS image or computer tomography scan finding. Preoperatively, we consulted the general surgeon routinely for the possible need for LECS in cases where perforation occurred (with perforation, the endoscopist could not seal the site with clips because of full-thickness resection) or the tumor was deemed unsuitable for complete resection via endoscopy alone. Perforation of the procedure was defined as any visible defects of the muscle layer during endoscopic resection. Perforation with laparoscopic cooperative surgery was defined as the need for surgical intervention for uncontrolled situations during endoscopic resection. Delayed perforation was defined as the presence of peritoneal signs and imaging evidence of perforation from the surgical site following a successful endoscopic resection procedure. Delayed bleeding was defined the presence of a coffee ground substance from the nasogastric tube, vomiting with bloody or coffee ground substance, or passage of tarry stool following the endoscopic resection procedure. All the patients received general anesthesia and at the operation room. Patients who received endoscopic mucosal resection (EMR) or with the intent of thoracoscopic surgery were excluded.

\subsection{Equipment and Procedure}

The equipment used for ESD included Olympus endoscopes (GIF-H260Z and GIF2TQ260M; Olympus Medical Systems Corp., Tokyo, Japan) with dual knife (KD-6501; Olympus Medical Systems Corp., Tokyo, Japan), IT Knife-2 (KD-612L; Olympus Medical Systems Corp., Tokyo, Japan), and an electrosurgical generator (ESG-100; Olympus Medical Systems Corp., Tokyo, Japan). The injection solution used to lift up the submucosal layer was composed of $10 \%$ glycerin and epinephrine $(1: 100,000)$. A CO $_{2}$ insufflation system (UCR; Olympus Medical Systems Corp., Tokyo, Japan) was used to reduce patient discomfort during the ESD procedure. A typical ESD procedure was performed with mucosal incision with exposure of the subepithelial lesion followed by resection of the lesion in an attempt of R0 resection. A submucosal tunneling endoscopic resection (STER) was performed with mucosal incision $2-3 \mathrm{~cm}$ above the target lesion and passing the endoscope into the submucosal space for tumor resection. The mucosal defect was subsequently closed with multiple clips. In cases involving incidental perforation or uncontrolled bleeding that 
could not be resolved by endoscopic clips or hemostasis, general surgeons took over the procedure and completed the procedure with laparoscopic cooperative surgery (LECS).

\subsection{Ethical Considerations}

The study protocol conforms to the ethical guidelines of the 1975 Declaration of Helsinki. The Ethics Committee of Changhua Christian Hospital approved our study protocol (CCH IRB No.: 210202), and informed consent was waived, considering the study's retrospective design.

\subsection{Statistical Analysis}

The extracted data were organized using Microsoft Excel and analyzed using MedCalc Statistical Software version 19.16 (MedCalc Software bvba, Ostend, Belgium; https: //www.medcalc.org; accessed on 1 December 2020) or $\mathrm{R}$ software $(\mathrm{R} \times 64$ 4.0.5, https: / /www.r-project.org/; accessed on 1 December 2020). The data was represented as mean SD or median (IQR) for continuous data and number (percentage \%) for category data. Furthermore, $p<0.05$ was considered statistically significant. The mean values of variables with non-normal distributions were compared using Mann-Whitney $U$ test. The frequencies of categorical variables were compared using Pearson's $\chi^{2}$ or Fisher's exact test, as appropriate.

The data were randomly divided into training data and test data at $66 \%$ and $34 \%$, respectively. To construct a prediction model for the need of LECS, we implemented a penalized logistic regression model and nomogram visualization in $\mathrm{R}$ software, with the use of clinical valuable features in the training dataset. The nomogram was constructed using the regression coefficient for each clinical valuable feature. The predictive accuracy and discriminative ability of the nomogram were determined by the area under the curve (AUC) and the calibration plot. For the calibration, we used the Hosmer-Lemeshow test, and compared the means of predicted salvage surgery with those of actual salvage surgery. The problem of overfitting was checked by three-fold cross-validation. Furthermore, the reliability of our nomogram was validated using independent test data.

\section{Results}

\subsection{Clinical Features of the Study Population}

This study analyzed 123 patients who underwent endoscopic resection for upper GI SETs between January 2012 and December 2020. Table 1 summarizes patients' characteristics and histopathologic details. The mean age was 55 years. Males accounted for $49.6 \%$. The average tumor size was $1.5 \mathrm{~cm}$. Most tumors were located in the gastric body $(n=35$, $28.4 \%)$, followed by the lower esophagus $(n=30,24.3 \%)$, cardia $(n=21,17 \%)$, fundus $(n=21,17.0 \%)$, antrum $(n=14,11.4 \%)$, and duodenum $(n=2,1.6 \%)$. Most SETs arose from the muscularis propria (69.1\%). Moreover, $56(45.5 \%), 42(34.1 \%) 8(6.5 \%)$, and $3(2.4 \%)$ patients had leiomyomas, GISTs, aberrant pancreases, and neuroendocrine tumors, respectively. En bloc resection was successfully performed in 114 (92.7\%) patients. The median follow-up duration was 242 days without recurrence. Tumors located in the esophagus, gastric fundus, and gastric cardia were mostly leiomyoma ( $n=25,83.3 \%)$, GISTs $(n=17$, $81.0 \%)$, and leiomyoma $(n=13,61.9 \%)$, respectively (Table 2$)$. GISTs were larger in size than leiomyomas or other tumors. 
Table 1. Characteristics of patients and their subepithelial tumors.

\begin{tabular}{|c|c|c|}
\hline & Characteristics & Number \\
\hline \multicolumn{2}{|c|}{ Median age, years (Median, IQR) } & $\begin{array}{c}55 \\
(48-60.75)\end{array}$ \\
\hline \multicolumn{3}{|l|}{ Sex, $n(\%)$} \\
\hline & Male & $61(49.6 \%)$ \\
\hline & Female & $62(50.4 \%)$ \\
\hline Hospital day, days (Me & IQR) & $6(5-8)$ \\
\hline Procedure time, minute & edian, IQR) & $60(30-90)$ \\
\hline \multicolumn{3}{|l|}{ Tumor location } \\
\hline & Esophagus & 30 \\
\hline & Gastric fundus & 21 \\
\hline & Gastric cardia & 21 \\
\hline & Gastric body & 35 \\
\hline & Gastric antrum & 14 \\
\hline & Duodenum & 2 \\
\hline Tumor size, cm (Media & & $1.5(1-2.5)$ \\
\hline \multicolumn{3}{|c|}{ Layer of tumor origin, $n(\%)$} \\
\hline & Submucosa & $38(30.9 \%)$ \\
\hline & Muscularis propria & $85(69.1 \%)$ \\
\hline \multicolumn{3}{|l|}{ Complications, $n(\%)$} \\
\hline & Perforation & $47(38.2 \%)$ \\
\hline & Perforation with laparoscopic cooperative surgery & $30(24.4 \%)$ \\
\hline & Delayed perforation & $1(0.8 \%)$ \\
\hline & Delayed bleeding & $1(0.8 \%)$ \\
\hline \multicolumn{3}{|l|}{ Pathology report, $n(\%)$} \\
\hline & Leiomyoma & $56(45.5 \%)$ \\
\hline & GIST & $42(34.1 \%)$ \\
\hline & Aberrant pancreas & $8(6.5 \%)$ \\
\hline & Neuroendocrine tumor & $3(2.4 \%)$ \\
\hline & Others* & $14(11.4 \%)$ \\
\hline En bloc resection rate & & $114(92.7 \%)$ \\
\hline Follow-up days, day ( & n, IQR) & $\begin{array}{c}242 \\
(69-774)\end{array}$ \\
\hline
\end{tabular}

* Others: glomangioma, elastofibroma, arteriovenous malformation, hemangioma, schwannoma, cavernous hemangioma, plexiform fibromyxoma, gastritis cystica profunda, lipoma. GIST, gastrointestinal stromal tumor; IQR, interquartile range.; Hospital day: Days from patient being admitted till patient being discharged. Follow-up days: Days from patient being discharged to the last clinical visit.

Table 2. Association of histopathology pattern and tumor location.

\begin{tabular}{lcccccc}
\hline & Esophagus & $\begin{array}{c}\text { Gastric } \\
\text { Fundus }\end{array}$ & $\begin{array}{c}\text { Gastric } \\
\text { Cardia }\end{array}$ & $\begin{array}{c}\text { Gastric } \\
\text { Body }\end{array}$ & $\begin{array}{c}\text { Gastric } \\
\text { Antrum }\end{array}$ & DuodenuSm \\
\hline GIST & 1 & 17 & 7 & 14 & 3 & 0 \\
Leiomyoma & 25 & 2 & 13 & 16 & 0 & 0 \\
Aberrant pancreas & 0 & 0 & 0 & 1 & 6 & 1 \\
Neuroendocrine & 0 & 0 & 0 & 2 & 0 & 1 \\
tumor & 4 & 2 & 1 & 5 & 0 \\
Others & & 2 & 2 & & \\
\hline
\end{tabular}

GIST, gastrointestinal stromal tumor.

\subsection{Analysis of Complication and Risk Factor Predictive for LECS}

Out of the 123 patients who received endoscopic resection, 47 had perforation intraoperatively, and 30 of them required LECS (Table 3). Meanwhile, one patient had delayed perforation with abdominal pain and pneumoperitoneum symptoms and underwent laparoscopic surgery on the next day after ESD. LECS was most likely required in GIST cases $(p=0.0049)$. Lesions located at the gastric body or fundus had a higher rate of LECS than other lesion sites $(32.6 \%$ vs. $1.5 \%, p<0.001)$. Perforation was unrelated to tumor size. However, LECS was likely required for larger tumors. 
Table 3. Comparison of patient features with or without LECS.

\begin{tabular}{lccc}
\hline & Without LECS & With LECS & $p$-Value \\
\hline Sex (M/F) & $47 / 46$ & $14 / 16$ & 0.7134 \\
Age, year (mean, SD) & $51.79(13.09)$ & $58.16(11.06)$ & 0.0018 \\
Size, cm (mean, SD) & $1.61(0.89)$ & $2.20(1.10)$ & 0.0003 \\
Site (E/Antrum/Body/Cardia/Fundus/D) & $30 / 13 / 26 / 17 / 5 / 2$ & $0 / 1 / 9 / 4 / 16 / 0$ & $<0.0001$ \\
Pathology (GIST/Leiomyoma/Others) & $22 / 49 / 22$ & $20 / 7 / 3$ & 0.0001 \\
Resection method (ESD/STER) & $78 / 15$ & $29 / 1$ & 0.0712 \\
\hline
\end{tabular}

D, duodenum; E, esophagus; ESD, endoscopic submucosal dissection; F, female; GIST, gastrointestinal stromal tumor; LECS, laparoscopic and endoscopic cooperative surgery; M, male; SD, standard deviation; STER, submucosal tunneling endoscopic resection.

\subsection{Development and Validation of the Nomogram}

To develop a prediction model for LECS requirement during endoscopic resection, we analyzed the LECS-associated clinical factors (Table 4). A nomogram was constructed using variables such as age, sex, SET location, and tumor size (Table 5). Figure 1 illustrates the nomogram for each factor. The AUCs of the training, validation, and test data were $0.893,0.816$, and 0.879 , respectively, implying a good discrimination ability (Figure 2). The nomogram was also well calibrated according to the calibration curve and HosmerLemeshow test results ( $p=0.9653$ and 0.8886 , respectively; Figure 3 ).

Table 4. Factors associated with LECS, according to univariable and multivariable analyses.

\begin{tabular}{|c|c|c|c|c|c|c|}
\hline & \multicolumn{3}{|c|}{ Univariable Analysis } & \multicolumn{3}{|c|}{ Multivariable Analysis } \\
\hline & cOR $(95 \% \mathrm{CI})$ & $p$-value & AUC & Coef. & adj. OR (95\% CI) & $p$-value \\
\hline Site & & & 0.820 & & & \\
\hline Others & 1 & & & & 1 & \\
\hline Gastric body & $3.57(0.68,18.65)$ & 0.132 & & 1.60 & $4.95(0.78,31.62)$ & 0.091 \\
\hline Gastric fundus & $100.8(6.36,1598.31)$ & 0.001 & & 4.25 & $70.32(3.74,1320.99)$ & 0.005 \\
\hline Size (per 1 unit increase) & $1.84(0.94,3.60)$ & 0.076 & 0.658 & 0.53 & $1.70(0.68,4.27)$ & 0.257 \\
\hline Age $\geq 55$ & $3.91(0.82,18.56)$ & 0.086 & 0.653 & 1.49 & $4.45(0.61,32.22)$ & 0.140 \\
\hline Female & $1.14(0.31,4.17)$ & 0.845 & 0.517 & -0.22 & $0.80(0.15,4.35)$ & 0.800 \\
\hline
\end{tabular}

AUC, area under the curve; CI, confidence interval; Coef., coefficient; cOR, crude odds ratio; LECS, laparoscopic and endoscopic cooperative surgery.

Table 5. Demographics of the training, cross-validation, and test data.

\begin{tabular}{lcccc}
\hline & Training Data & Validation Data & Test Data & $p$-Value \\
\hline Sample size & 54 & 28 & 41 & \\
Age, years & $54.89 \pm 10.55$ & $50.07 \pm 12.57$ & $53.56 \pm 15.51$ & 0.275 \\
$\quad<55$ & $23(42.59 \%)$ & $16(57.14 \%)$ & $20(48.78 \%)$ & 0.454 \\
$\quad \geq 55$ & $31(57.41 \%)$ & $12(42.86 \%)$ & $21(51.22 \%)$ & \\
Sex & & & & \\
$\quad$ Female & $28(51.85 \%)$ & $15(53.57 \%)$ & $19(46.34 \%)$ & 0.807 \\
$\quad$ Male & $26(48.15 \%)$ & $13(46.43 \%)$ & $22(53.66 \%)$ & \\
Site & & & & \\
Gastric fundus & $5(9.26 \%)$ & $3(10.71 \%)$ & $13(31.71 \%)$ & 0.041 \\
Gastric body & $18(33.33 \%)$ & $7(25 \%)$ & $10(24.39 \%)$ & \\
Others & $31(57.41 \%)$ & $18(64.29 \%)$ & $18(43.9 \%)$ & \\
Size, cm & $1.87 \pm 1.04$ & $1.67 \pm 0.94$ & $1.66 \pm 0.92$ & 0.516 \\
$\quad<1$ & $10(18.52 \%)$ & $6(21.43 \%)$ & $10(24.39 \%)$ & 0.811 \\
$\quad \geq 1$ to $<2$ & $23(42.59 \%)$ & $14(50 \%)$ & $18(43.9 \%)$ & \\
$\geq 2$ to $<3$ & $10(18.52 \%)$ & $5(17.86 \%)$ & $9(21.95 \%)$ & \\
3 & $11(20.37 \%)$ & $3(10.71 \%)$ & $4(9.76 \%)$ & \\
LCES & & & & \\
$\quad$ No & $43(79.63 \%)$ & $21(75 \%)$ & $29(70.73 \%)$ & 0.604 \\
$\quad$ Yes & $11(20.37 \%)$ & $7(25 \%)$ & $12(29.27 \%)$ & \\
\hline
\end{tabular}

LCES: laparoscopic and endoscopic cooperative surgery. 


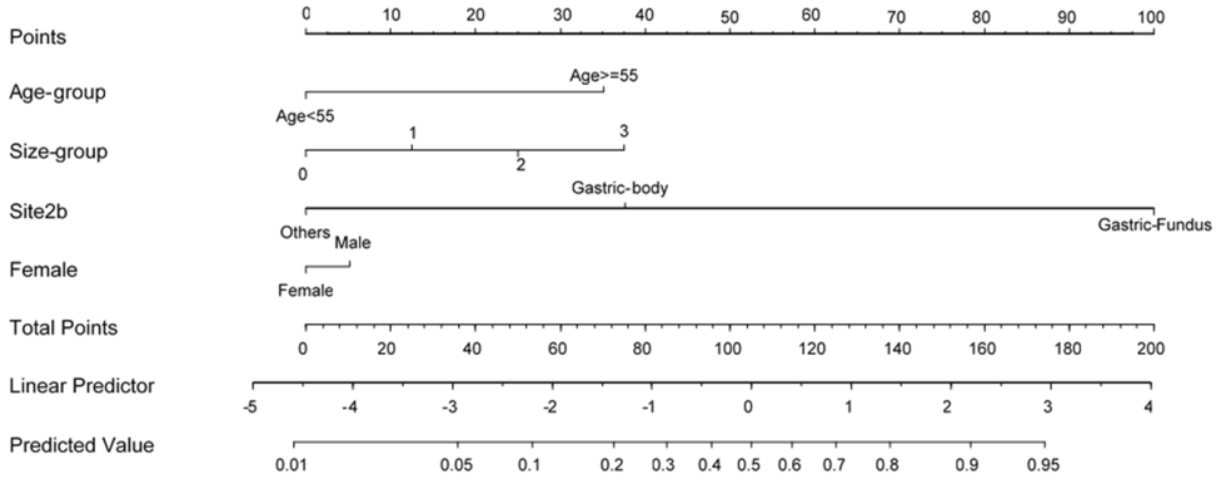

Figure 1. Nomogram of the prediction model.

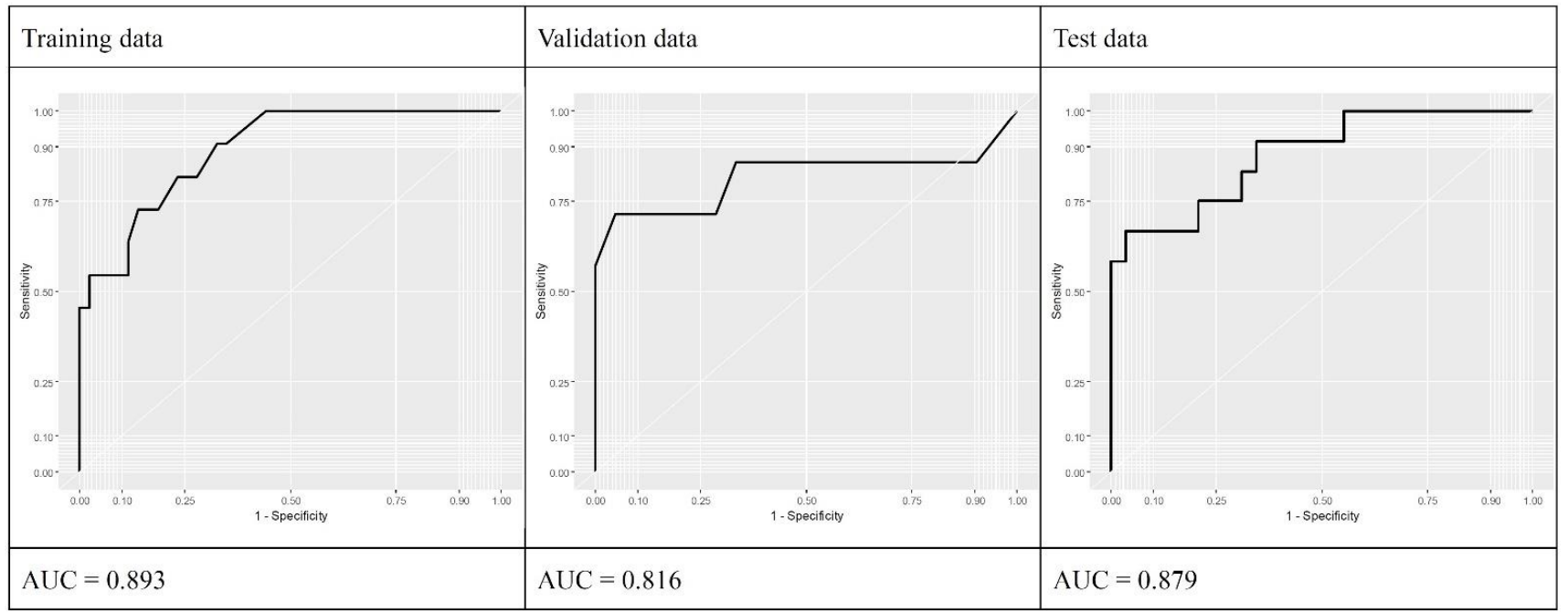

Figure 2. ROC analysis for predicting LECS requirement during endoscopic resection.

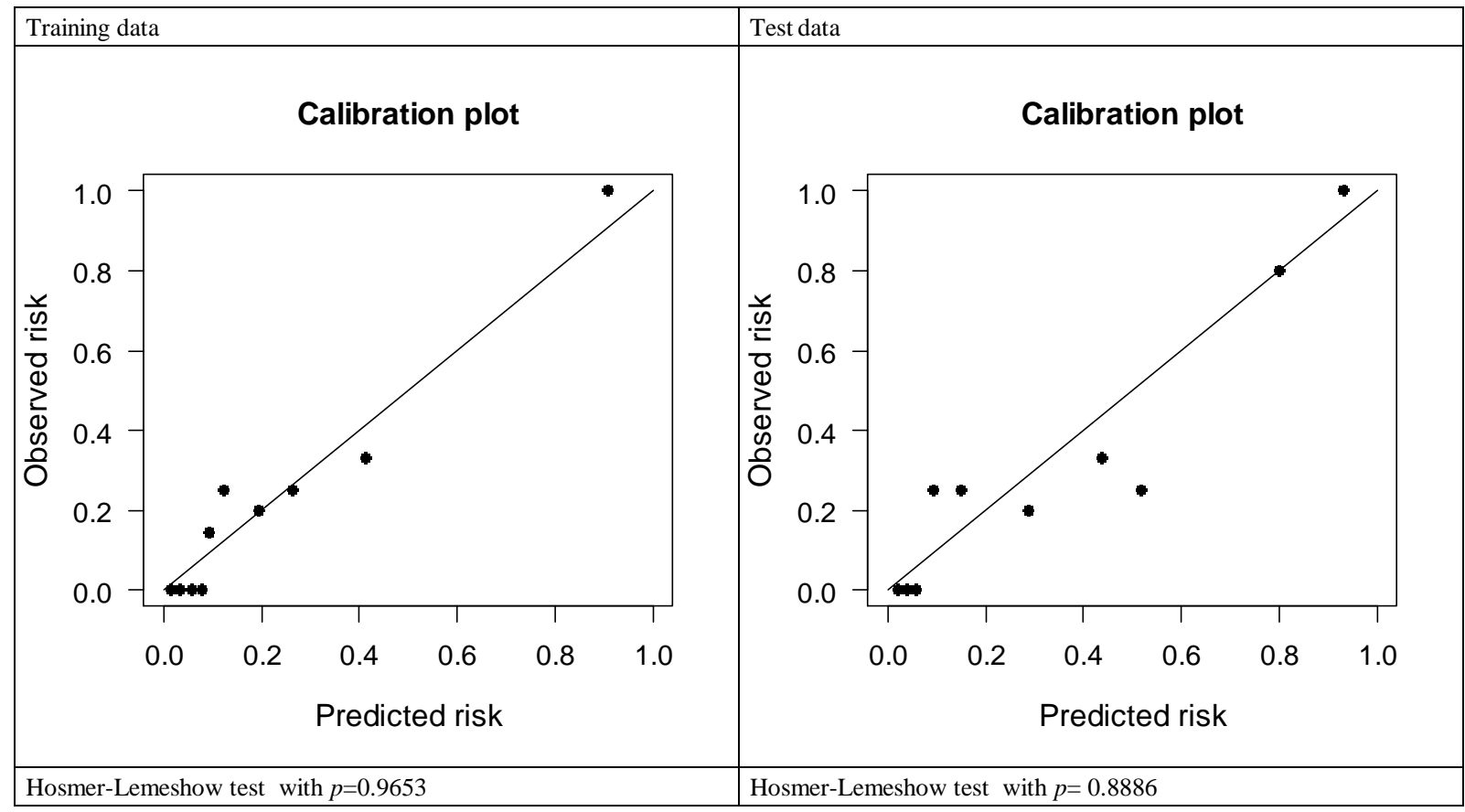

Figure 3. Calibration plot for predicting LECS requirement during endoscopic resection. 


\section{Discussion}

As the amount of screening increases, the incidental identification of GISTs also increases, and this tumor type has become a common problem, especially for lesions $<2 \mathrm{~cm}[5,10]$. Owing to the low risk of disease progression, surveillance endoscopy alone is recommended; unfortunately, patient compliance is poor [11]. With the advancement of endoscopic resection techniques, endoscopic and/or laparoscopic management of these lesions has become possible. In this study, we evaluated a large case series in a single institution and developed a prediction model for LECS requirement during the endoscopic management of GI SETs [12-14].

GIST, which is a common gastric SET, has variations of malignant potential depending on tumor size and mitotic rate [15]. The most common location of malignant/potentially malignant SETs was the gastric body $(78.1 \%)$, followed by the fundus $(15.6 \%)$. In particular, GISTs were frequently found in the gastric body $(25 / 31,80.6 \%)$ and fundus $(4 / 31$, $12.9 \%$ ) [16]. In our analysis, GISTs were mostly found at the gastric fundus. Meanwhile, leiomyomas were mostly located at the gastric cardia and esophagus.

The United States National Comprehensive Cancer Network and the Asian consensus guidelines suggested that surgical resection is strongly recommended when the tumor is $\geq 20 \mathrm{~mm}$, is growing, or has malignancy signs, such as irregular margins, ulceration, bleeding, cystic change, necrosis, or heterogeneous echogenicity in endoscopy and/or EUS [4,17]. However, a small GIST size $(<20 \mathrm{~mm})$ has also malignancy potential. One study suggested $14 \mathrm{~mm}$ as a reasonable cutoff size for small GISTs because of significant tumor progression [18]. In our study, GISTs were highly mitotic when the tumor size was $<2 \mathrm{~cm}$ (1/14 patients, $7.1 \%)$ and annual surveillance alone may be inadequate.

Furthermore, endoscopic resection was a safe alternative to surgical resection for removing upper GI SETs, especially for those with highly suspected GISTs clinically or with tumor size $>2 \mathrm{~cm}$ [9]. However, perforation remains one of the major complications during ESD. With the improvement of endoscopic techniques, small perforations may be successfully sealed with clips intraoperatively. Large perforations may need laparoscopic surgery, with increased complication rates and prolonged hospitalization days [5,13,19-21]. The perforation rate during ESD for SET is reportedly 4-27.2\% [9,22-27]. The perforation rate was significantly higher in the upper third of the stomach [9], particularly the fundus [23], and when the tumor invades the muscularis propria $[25,27,28]$. As we defined the perforation as any visible defects of the muscle layer fiber, to achieve a R0 resection, we encountered a higher rate of perforation in the present study.

In STER, which is a modified form of peroral endoscopic myotomy for esophageal achalasia [29], a submucosal tunnel is created for tumor resection. STER can resect SETs even with muscularis propria invasion and can well-preserve the clipped overlying mucosa [30,31]. A meta-analysis with 12 studies evaluated the safety of STER for SETs in 701 patients and found that the most common complications were subcutaneous emphysema and pneumomediastinum, with a perforation rate of $0.6 \%$ [32]. In our analysis, only 1 of 16 patients received salvage laparoscopic surgery after STER. Most tumors were located at the esophagus, gastric cardia, and gastric body. Tumors located at the gastric fundus were unsuitable for STER because of the sharp angle of the endoscopy approach and the difficulty in identifying tumor location at the submucosal tunnel.

In our institution, GISTs accounted for $81.0 \%$ of fundal SETs, and LECS was frequently demanded to avoid tumor seeding and local recurrence. Using a full-thickness resection device is potentially beneficial to solve such problems. Meanwhile, endoscopic full-thickness resection using novel devices, such as over-the-scope clip (OTSC) and overstitch endoscopic suturing system, is possible for SET resection without laparoscopic assistance [33-35]. However, these new devices are not all available in Taiwan, as well as in some other countries. Therefore, LECS is still required in our series, accounting for the high perforation/operation rate, especially in the gastric fundus. Furthermore, some retrospective studies reported a safe method for LECS for gastric SET that does not depend on the tumor location, such as the esophagogastric junction or pyloric ring [36-38]. 
As shown in our analysis, endoscopic resection is less invasive for small upper-GI SETs, and most perforations could be successfully managed by an endoscopic method. Meanwhile, LECS requires additional manpower during upper-GI SET management. Currently, we do not have a model that can help predict LECS requirement. In the present study, we developed a nomogram used for predicting the need for LECS. The nomogram is practical and highly accurate. For SETs that are highly likely to require LECS, using such a nomogram could help the endoscopist communicate with the surgeon and the patient regarding the treatment plan before the endoscopic resection, especially when the OTSC and overstitch endoscopic suturing systems are unavailable.

However, this study has some limitations [39,40]. First, this is a single-center study with a small sample size. Further large-scale studies are required to validate the usefulness of this nomogram for clinical use. Second, this study is retrospective and possibly has some selection biases. Not all upper-GI SETs were enrolled for endoscopic resection. Third, endoscopic resection, either ESD or STER, requires high-technology methods only experienced endoscopists could perform. In this study, two experienced endoscopist with at least 100 annual ESD experiences for colon neoplasms or upper-GI neoplasms performed the endoscopic resection. Thus, this nomogram could be useful for shared decision making with patients even with less experienced endoscopists preoperatively.

\section{Conclusions}

Endoscopic resection is noninvasive and safe for treating upper-GI SETs. The prediction model for LECS requirement is useful for endoscopists when communicating with the surgeon and the patient before endoscopic resection.

Author Contributions: Conceptualization, S.-W.H., H.-H.Y.; methodology, M.-W.C., C.-T.K. and S.P.H.; validation, C.-T.K.; formal analysis, C.-T.K.; investigation, S.-W.H., C.-W.Y., K.-H.L. and Y.-Y.C.; resources, H.-H.Y.; data curation, S.-W.H., M.-W.C. and S.-P.H.; writing-original draft preparation, S.-W.H.; writing-review and editing, H.-H.Y., M.-W.C., Y.-Y.C. All authors have read and agreed to the published version of the manuscript.

Funding: The authors received research grand from Changhua Christian Hospital (109-CCH-IRP-008 and 110-CCH-IRP-020).

Institutional Review Board Statement: The study was conducted according to the guidelines of the Declaration of Helsinki, and approved by the Institutional Review Board of Changhua Christian Hospital (protocol code CCH IRB: 210202 and date of approval: 15 March 2021). Patient consent was waived by the institutional review board due to retrospective nature of the present study.

Data Availability Statement: The datasets generated and/or analyzed during the current study are not publicly available, but these may be requested from the corresponding author, upon reasonable request.

Conflicts of Interest: The authors declare no conflict of interest.

\section{References}

1. Hedenbro, J.L.; Ekelund, M.; Wetterberg, P. Endoscopic diagnosis of submucosal gastric lesions. Surg. Endosc. 1991, 5, 20-23. [CrossRef]

2. Lee, J.H.; Lee, H.L.; Ahn, Y.W.; Lee, K.N.; Jun, D.W.; Lee, O.Y.; Han, D.S.; Yoon, B.C.; Choi, H.S. Prevalence of Gastric Subepithelial Tumors in Korea: A Single Center Experience. Korean J. Gastroenterol. 2015, 66, 274-276. [CrossRef] [PubMed]

3. Hwang, J.H.; Saunders, M.D.; Rulyak, S.J.; Shaw, S.; Nietsch, H.; Kimmey, M.B. A prospective study comparing endoscopy and EUS in the evaluation of GI subepithelial masses. Gastrointest. Endosc. 2005, 62, 202-208. [CrossRef]

4. Demetri, G.D.; Von Mehren, M.; Antonescu, C.R.; DeMatteo, R.P.; Ganjoo, K.N.; Maki, R.G.; Pisters, P.W.; Raut, C.P.; Riedel, R.F.; Schuetze, S.; et al. NCCN Task Force Report: Update on the Management of Patients with Gastrointestinal Stromal Tumors. J. Natl. Compr. Cancer Netw. 2010, 8, S1-S44. [CrossRef] [PubMed]

5. Faulx, A.L.; Kothari, S.; Acosta, R.D.; Agrawal, D.; Bruining, D.H.; Chandrasekhara, V.; Eloubeidi, M.A.; Fanelli, R.D.; Gurudu, S.R.; Khashab, M.A.; et al. The role of endoscopy in subepithelial lesions of the GI tract. Gastrointest. Endosc. 2017, 85, 1117-1132. [CrossRef]

6. Nishida, T.; Goto, O.; Raut, C.P.; Yahagi, N. Diagnostic and treatment strategy for small gastrointestinal stromal tumors. Cancer 2016, 122, 3110-3118. [CrossRef] 
7. Honda, M.; Hiki, N.; Nunobe, S.; Ohashi, M.; Kiyokawa, T.; Sano, T.; Yamaguchi, T. Long-term and surgical outcomes of laparoscopic surgery for gastric gastrointestinal stromal tumors. Surg. Endosc. 2014, 28, 2317-2322. [CrossRef]

8. Chung, I.-K.; Lee, J.H.; Lee, S.-H.; Kim, S.-J.; Cho, J.Y.; Cho, W.Y.; Hwangbo, Y.; Keum, B.R.; Park, J.J.; Chun, H.-J.; et al. Therapeutic outcomes in 1000 cases of endoscopic submucosal dissection for early gastric neoplasms: Korean ESD Study Group multicenter study. Gastrointest. Endosc. 2009, 69, 1228-1235. [CrossRef]

9. Białek, A.; Wiechowska-Kozłowska, A.; Pertkiewicz, J.; Polkowski, M.; Milkiewicz, P.; Karpińska, K.; Ławniczak, M.; Starzyńska, T. Endoscopic submucosal dissection for treatment of gastric subepithelial tumors (with video). Gastrointest. Endosc. 2012, 75, 276-286. [CrossRef] [PubMed]

10. Aslanian, H.R.; Sethi, A.; Bhutani, M.S.; Goodman, A.; Krishnan, K.; Lichtenstein, D.R.; Melson, J.; Navaneethan, U.; Pannala, R.; Parsi, M.A.; et al. ASGE guideline for endoscopic full-thickness resection and submucosal tunnel endoscopic resection. VideoGIE 2019, 4, 343-350. [CrossRef] [PubMed]

11. Kushnir, V.M.; Keswani, R.N.; Hollander, T.G.; Kohlmeier, C.; Mullady, D.K.; Azar, R.R.; Murad, F.M.; Komanduri, S.; Edmundowicz, S.A.; Early, D.S. Compliance with surveillance recommendations for foregut subepithelial tumors is poor: Results of a prospective multicenter study. Gastrointest. Endosc. 2015, 81, 1378-1384. [CrossRef]

12. Lee, I.-L.; Lin, P.Y.; Tung, S.-Y.; Shen, C.-H.; Wei, K.-L.; Wu, C.-S. Endoscopic submucosal dissection for the treatment of intraluminal gastric subepithelial tumors originating from the muscularis propria layer. Endoscopy 2006, 38, 1024-1028. [CrossRef] [PubMed]

13. Chu, Y.-Y.; Lien, J.-M.; Tsai, M.-H.; Chiu, C.-T.; Chen, T.-C.; Yang, K.-C.; Ng, S.-C. Modified endoscopic submucosal dissection with enucleation for treatment of gastric subepithelial tumors originating from the muscularis propria layer. BMC Gastroenterol. 2012, 12, 124. [CrossRef] [PubMed]

14. Chen, T.-H.; Hsu, C.-M.; Chu, Y.-Y.; Wu, C.-H.; Chen, T.-C.; Hsu, J.-T.; Yeh, T.-S.; Lin, C.-J.; Chiu, C.-T. Association of endoscopic ultrasonographic parameters and gastrointestinal stromal tumors (GISTs): Can endoscopic ultrasonography be used to screen gastric GISTs for potential malignancy? Scand. J. Gastroenterol. 2016, 51, 374-377. [CrossRef] [PubMed]

15. Agaimy, A. Gastrointestinal stromal tumors (GIST) from risk stratification systems to the new TNM proposal: More questions than answers? A review emphasizing the need for a standardized GIST reporting. Int. J. Clin. Exp. Pathol. 2010, 3, 461-471. [PubMed]

16. Kim, S.Y.; Shim, K.-N.; Lee, J.-H.; Lim, J.Y.; Kim, T.O.; Choe, A.R.; Tae, C.H.; Jung, H.-K.; Moon, C.M.; Kim, S.-E.; et al. Comparison of the Diagnostic Ability of Endoscopic Ultrasonography and Abdominopelvic Computed Tomography in the Diagnosis of Gastric Subepithelial Tumors. Clin. Endosc. 2019, 52, 565-573. [CrossRef]

17. Koo, D.-H.; Ryu, M.-H.; Kim, K.-M.; Yang, H.-K.; Sawaki, A.; Hirota, S.; Zheng, J.; Zhang, B.; Tzen, C.-Y.; Yeh, C.-N.; et al. Asian Consensus Guidelines for the Diagnosis and Management of Gastrointestinal Stromal Tumor. Cancer Res. Treat. 2016, 48, 1155-1166. [CrossRef] [PubMed]

18. Fang, Y.-J.; Cheng, T.-Y.; Sun, M.-S.; Yang, C.-S.; Chen, J.-H.; Liao, W.-C.; Wang, H.-P. Suggested cutoff tumor size for management of small EUS-suspected gastric gastrointestinal stromal tumors. J. Formos. Med. Assoc. 2012, 111, 88-93. [CrossRef] [PubMed]

19. Yen, H.-H.; Wu, P.-Y.; Su, P.-Y.; Yang, C.-W.; Chen, Y.-Y.; Chen, M.-F.; Lin, W.-C.; Tsai, C.-L.; Lin, K.-P. Performance Comparison of the Deep Learning and the Human Endoscopist for Bleeding Peptic Ulcer Disease. J. Med. Biol. Eng. 2021, 41, 504-513. [CrossRef]

20. Yang, C.-W.; Yen, H.-H.; Chen, Y.-Y.; Soon, M.-S. Use of Dual Knife for Large Pedunculated Colorectal Polyps. Surg. Laparosc. Endosc. Percutaneous Tech. 2014, 24, 444-447. [CrossRef] [PubMed]

21. Yang, C.-W.; Yen, H.-H.; Chen, Y.-Y.; Soon, M.-S.; Chen, C.-J. Novel Use of the Tip of a Standard Diathermic Snare for Endoscopic Submucosal Dissection of a Large Gastric Adenomatous Polyp. J. Laparoendosc. Adv. Surg. Tech. 2012, 22, 910-912. [CrossRef]

22. Lee, J.S.; Kim, G.H.; Park, Y.; Yoon, J.M.; Kim, T.W.; Seo, J.H.; Lee, B.E.; Song, G.A. Endoscopic Submucosal Dissection for Gastric Subepithelial Tumors: A Single-Center Experience. Gastroenterol. Res. Pract. 2015, 2015, 425469. [CrossRef] [PubMed]

23. Du Jeong, I.; Jung, S.W.; Bang, S.-J.; Shin, J.W.; Park, N.H.; Kim, D.H. Endoscopic enucleation for gastric subepithelial tumors originating in the muscularis propria layer. Surg. Endosc. 2010, 25, 468-474. [CrossRef] [PubMed]

24. Chun, S.Y.; Kim, K.O.; Park, D.S.; Lee, I.J.; Park, J.W.; Moon, S.-H.; Baek, I.H.; Kim, J.H.; Park, C.K.; Kwon, M.J. Endoscopic submucosal dissection as a treatment for gastric subepithelial tumors that originate from the muscularis propria layer: A preliminary analysis of appropriate indications. Surg. Endosc. 2013, 27, 3271-3279. [CrossRef]

25. Li, L.; Wang, F.; Wu, B.; Wang, Q.; Wang, C.; Liu, J. Endoscopic submucosal dissection of gastric fundus subepithelial tumors originating from the muscularis propria. Exp. Ther. Med. 2013, 6, 391-395. [CrossRef]

26. Catalano, F.; Rodella, L.; Lombardo, F.; Silano, M.; Tomezzoli, A.; Fuini, A.; Di Cosmo, M.A.; de Manzoni, G.; Trecca, A. Endoscopic submucosal dissection in the treatment of gastric submucosal tumors: Results from a retrospective cohort study. Gastric Cancer 2013, 16, 563-570. [CrossRef]

27. Zhang, Y.; Ye, L.-P.; Zhou, X.-B.; Mao, X.-L.; Zhu, L.-H.; He, B.-L.; Huang, Q. Safety and Efficacy of Endoscopic Excavation for Gastric Subepithelial Tumors Originating From the Muscularis Propria Layer. J. Clin. Gastroenterol. 2013, 47, 689-694. [CrossRef]

28. Ye, L.-P.; Zhu, L.-H.; Zhou, X.-B.; Mao, X.-L.; Zhang, Y. Endoscopic excavation for the treatment of small esophageal subepithelial tumors originating from the muscularis propria. Hepatogastroenterology 2015, 62, 65-68.

29. Inoue, H.; Minami, H.; Kobayashi, Y.; Sato, Y.; Kaga, M.; Suzuki, M.; Satodate, H.; Odaka, N.; Itoh, H.; Kudo, S. Peroral endoscopic myotomy (POEM) for esophageal achalasia. Endoscopy 2010, 42, 265-271. [CrossRef] 
30. Inoue, H.; Ikeda, H.; Hosoya, T.; Onimaru, M.; Yoshida, A.; Eleftheriadis, N.; Maselli, R.; Kudo, S. Submucosal endoscopic tumor resection for subepithelial tumors in the esophagus and cardia. Endoscopy 2012, 44, 225-230. [CrossRef] [PubMed]

31. Xu, M.-D.; Cai, M.-Y.; Zhou, P.-H.; Qin, X.-Y.; Zhong, Y.-S.; Chen, W.-F.; Hu, J.-W.; Zhang, Y.-Q.; Ma, L.-L.; Qin, W.-Z.; et al. Submucosal tunneling endoscopic resection: A new technique for treating upper GI submucosal tumors originating from the muscularis propria layer (with videos). Gastrointest. Endosc. 2012, 75, 195-199. [CrossRef] [PubMed]

32. Peng, W.; Tan, S.; Huang, S.; Ren, Y.; Li, H.; Peng, Y.; Fu, X.; Tang, X. Efficacy and safety of submucosal tunneling endoscopic resection for upper gastrointestinal submucosal tumors with more than 1-year' follow-up: A systematic review and meta-analysis. Scand. J. Gastroenterol. 2019, 54, 397-406. [CrossRef]

33. Schmidt, A.; Bauder, M.; Riecken, B.; Von Renteln, D.; Muehleisen, H.; Caca, K. Endoscopic full-thickness resection of gastric subepithelial tumors: A single-center series. Endoscopy 2014, 47, 154-158. [CrossRef] [PubMed]

34. Sarker, S.; Gutierrez, J.P.; Council, L.; Brazelton, J.D.; Baig, K.R.K.K.; Mönkemüller, K. Over-the-scope clip-assisted method for resection of full-thickness submucosal lesions of the gastrointestinal tract. Endoscopy 2014, 46, 758-761. [CrossRef] [PubMed]

35. Azzolini, F.; Cecinato, P.; Iori, V.; De Marco, L.; Sassatelli, R. Endoscopic full-thickness resection for suspected residual rectal neuroendocrine tumor and closure of the defect with a new suturing system. Endoscopy 2015, 47, E556-E557. [CrossRef]

36. Hiki, N.; Yamamoto, Y.; Fukunaga, T.; Yamaguchi, T.; Nunobe, S.; Tokunaga, M.; Miki, A.; Ohyama, S.; Seto, Y. Laparoscopic and endoscopic cooperative surgery for gastrointestinal stromal tumor dissection. Surg. Endosc. 2008, 22, 1729-1735. [CrossRef] [PubMed]

37. Hoteya, S.; Haruta, S.; Shinohara, H.; Yamada, A.; Furuhata, T.; Yamashita, S.; Kikuchi, D.; Mitani, T.; Ogawa, O.; Matsui, A.; et al. Feasibility and safety of laparoscopic and endoscopic cooperative surgery for gastric submucosal tumors, including esophagogastric junction tumors. Dig. Endosc. 2014, 26, 538-544. [CrossRef]

38. Aoyama, J.; Kawakubo, H.; Matsuda, S.; Mayanagi, S.; Fukuda, K.; Irino, T.; Nakamura, R.; Wada, N.; Kitagawa, Y. Clinical outcomes of laparoscopic and endoscopic cooperative surgery for submucosal tumors on the esophagogastric junction: A retrospective single-center analysis. Gastric Cancer 2020, 23, 1084-1090. [CrossRef]

39. Yen, H.H.; Su, P.Y.; Huang, S.P.; Wu, L.; Hsu, T.C.; Zeng, Y.H.; Chen, Y.Y. Evaluation of non-alcoholic fatty liver disease in patients with inflammatory bowel disease using controlled attenuation parameter technology: A Taiwanese retrospective cohort study. PLOS ONE 2021, 16, e0252286. [CrossRef]

40. Chang, Y.-Y.; Li, P.-C.; Chang, R.-F.; Yao, C.-D.; Chen, Y.-Y.; Chang, W.-Y.; Yen, H.-H. Deep learning-based endoscopic anatomy classification: An accelerated approach for data preparation and model validation. Surg. Endoscopy 2021. [CrossRef] 